\title{
MANEJO E VIABILIDADE ECONÔMICA DA IRRIGAÇÃO POR GOTEJAMENTO NA CULTURA DO CAFEEIRO ACAIÁ CONSIDERANDO SEIS SAFRAS ${ }^{1}$
}

\author{
EDNALDO L. DE OLIVEIRA ${ }^{2}$, MANOEL A. DE FARIA ${ }^{3}$, RICARDO P. REIS ${ }^{4}$, \\ MIRIAN DE L. O. E SILVA ${ }^{5}$
}

\begin{abstract}
RESUMO: Este trabalho teve como objetivo estudar técnica e economicamente o efeito da irrigação por gotejamento na produção do cafeeiro (Coffea arabica L.) Acaiá MG-1474. O delineamento experimental utilizado foi o de blocos casualizados, com cinco tratamentos e quatro repetições. Os tratamentos foram: $\mathrm{L}_{0}=$ sem irrigação; $\mathrm{L}_{40}=40 \% ; \mathrm{L}_{60}=60 \% ; \mathrm{L}_{80}=80 \%$ e $\mathrm{L}_{100}=$ $100 \%$ da Evaporação do Tanque Classe A (ECA). Para realizar a análise econômica, utilizou-se dos dados de produção acumulada das seis primeiras safras: 1999, 2000, 2001, 2002, 2003 e 2004 . A análise dos custos da lavoura irrigada foi baseada na teoria dos custos de produção. A produtividade média dos tratamentos foi de 52,88; 66,99; 70,00; 71,93 e 79,50 sacas por hectare, para $\mathrm{L}_{0}, \mathrm{~L}_{40}, \mathrm{~L}_{60}$, $\mathrm{L}_{80}$ e $\mathrm{L}_{100}$, respectivamente. Considerando o preço da saca de café a $\mathrm{R} \$ 212,00$, a situação econômica analisada mostrou que, neste nível de preço, é economicamente viável a produção de café, quer seja irrigado, quer não, sendo que, para os tratamentos irrigados, o manejo da irrigação, com a lâmina de reposição de $100 \%$ da Evaporação do Tanque Classe A, proporcionou maiores lucros.
\end{abstract}

PALAVRAS-CHAVE: custo de produção, Acaiá MG-1474, cafeicultura irrigada.

\section{ECONOMIC VIABILITY AND MANAGEMENT OF DRIP IRRIGATION IN “ACAIÁ”COFFEE PLANTS FOR SIX HARVESTS}

\begin{abstract}
The objective of present work was study the effect of drip irrigation on production of coffee plant (Coffea arabica L) Acaiá MG-1474. The experimental design was randomized blocks, with five treatments and four replications. The treatments were: $\mathrm{L}_{0}=$ without irrigation, $\mathrm{L}_{40}=$ $40 \%, \mathrm{~L}_{60}=60 \%, \mathrm{~L}_{80}=80 \%$ and $\mathrm{L}_{100}=100 \%$ of the evaporation from a Class A pan evaporation (ECA). An economic analysis was done for production of the years 1999, 2000, 2001, 2002, 2003 and 2004. The costs analysis of the irrigated treatments was based on the theory of the production costs. There was good technical efficiency, once the mean productivity of each treatment was 52.88, 66.99, 70.00, 71.93 and 79.50 bags of $60 \mathrm{~kg}$ per hectare, for the treatments L1, L2, L3, L4 and L0, respectively. Economic analysis showed that, for a price of $\mathrm{R} \$ 212.00$ per bag, the coffee production is practicable, for irrigated and non irrigated crops. A water replacement of $100 \%$ of the evaporation provided the best profit..
\end{abstract}

KEYWORDS: production cost, Acaiá MG-1474, irrigated coffee.

\footnotetext{
${ }^{1}$ Subprojeto 19.2002.317.04 financiado pela Embrapa - CBP\&D/Café

${ }^{2}$ Eng $^{\mathrm{o}}$ Agrônomo, Prof. Doutor, IFNGM, Câmpus Araçuaí - MG.

${ }^{3}$ Prof. Titular, Departamento de Engenharia, UFLA, Lavras - MG.

${ }^{4}$ Prof. Titular, Departamento de Administração e Economia, UFLA, Lavras - MG.

${ }^{5}$ Eng $^{\mathrm{a}}$ Agrícola, Doutora, bolsista do PNP\&D/Café junto ao DEG/UFLA, Lavras - MG.

Recebido pelo Conselho Editorial em: 25-8-2008

Aprovado pelo Conselho Editorial em: 20-7-2010
} 


\section{INTRODUÇÃO}

A cafeicultura brasileira tem sofrido mudanças significativas, principalmente em seu sistema de produção. Dentre essas mudanças, pode-se destacar a utilização da irrigação, que pode proporcionar menos riscos, mais eficiência na utilização e aplicação de insumos, além de maior produtividade e melhor qualidade do produto.

Em decorrência da busca por maiores produtividades e competitividade no agronegócio do café, verificou-se no setor a utilização de sistemas de produção inovadores, buscando aumento da competitividade por meio da diferenciação de mercado pela qualidade, redução de custos via elevação de produtividade e adoção de novas tecnologias de produção (MARTIN et al., 1995; GROSSI, 1998).

Regiões climaticamente aptas para o cultivo de café, como o sul de Minas Gerais, vêm sofrendo o efeito de estiagens prolongadas nos períodos críticos de demanda de água pela planta, promovendo queda na produção de várias lavouras (ALVES, 1999). Apesar da maior concentração das áreas irrigadas em regiões onde existem restrições hídricas importantes em períodos extensos do ano, é grande também a implantação de projetos de irrigação em áreas tradicionais de cafeicultura, como regiões do Sul e da Zona da Mata de Minas Gerais e diversas regiões do Estado de São Paulo (MANTOVANI \& SOARES, 2003).

Dentre os sistemas de irrigação existentes, destacam-se a irrigação por aspersão convencional, autopropelido, pivô-central e o gotejamento. É importante destacar que não existe um método melhor que o outro em relação à fisiologia da planta, segundo FARIA \& REZENDE (1997), porém eles diferem na sua adaptabilidade em relação às condições locais de solo, topografia, clima, cultura, qualidade de água, fatores econômicos e determinadas influências externas e agronômicas. Cada sistema apresenta suas vantagens e desvantagens, porém SANTINATO et al. (1996) citam como o mais indicado para a cafeicultura irrigada, o sistema de gotejamento.

Independentemente do sistema de irrigação utilizado, a literatura é unânime ao enfatizar a importância de se controlar adequadamente a aplicação, otimizando o custo de água e energia e de outros fatores envolvidos na condução de uma cultura irrigada (FARIA \& REZENDE, 1997).

Diante das mudanças estruturais da cafeicultura, são numerosas as propostas de sistemas de produção inovadores que buscam aumento da competitividade via qualidade, automação, entre outras tecnologias. Como essas propostas envolvem investimentos e alterações nas práticas tradicionalmente utilizadas, é natural que existam dúvidas quanto ao seu mérito econômico, quando consideradas as características peculiares de uma dada região produtora.

O custo de produção é um dos principais indicadores que servem como parâmetro e auxiliam o empresário cafeicultor na sua tomada de decisão, pois, na cafeicultura, vários fatores contribuem para a formação do custo de produção, o que certamente vai definir o sucesso ou não do empresário cafeicultor na exploração desta atividade. Entretanto, é polêmica a questão de custo de produção na cafeicultura brasileira, o que leva a diferentes respostas fornecidas, as quais, se não interpretadas e empregadas corretamente nas expressões matemáticas, podem interferir, posteriormente, em maiores erros de estimação dos custos. Do mesmo modo, a omissão de respostas corretas sobre as técnicas empregadas e os investimentos realizados, nas propriedades, também interferem significativamente nas estimativas (REIS, 2002).

$\mathrm{Na}$ agricultura irrigada, uma produção eficiente e rentável deve constituir o principal objetivo econômico, buscando sempre receitas maiores que os custos ou, no mínimo, que as receitas e despesas sejam iguais. Desta maneira, é importante conhecer o grau de risco envolvido na aquisição de novas tecnologias. Estes riscos são decorrentes de incertezas econômicas proporcionadas pela variação do preço de venda do produto, taxa de juros, custos da água, vida útil do sistema de irrigação e taxa de manutenção ocorrida com o manejo do sistema de irrigação, bem como variação na produtividade ao longo dos anos. Entretanto, a viabilidade econômica é um fator indispensável para sua adoção entre os agricultores (FRIZZONE et al., 1994; BASTOS et al., 2000). A agricultura 
irrigada exige alto investimento, principalmente em obras e aquisição de equipamentos, em transporte, em controle e distribuição de água, além de gastos com energia e mão de obra para operação do sistema, que representam importantes custos adicionais, que devem ser pagos pelo incremento de produtividade proporcionado pela irrigação (RODRIGUEZ, 1990).

Assim, a irrigação é uma tecnologia que requer investimentos significativos e está associada à utilização intensiva de insumos, tornando importante a análise econômica dos componentes envolvidos no sistema (SILVA et al., 2003).

Diante do exposto, este trabalho foi desenvolvido tendo como objetivo avaliar o manejo da água de irrigação em função do balanço entre a evaporação do Tanque Classe A e precipitação, bem como analisar a viabilidade econômica da irrigação por gotejamento na cultura do cafeeiro em Lavras - MG, após seis safras consecutivas (1999, 2000, 2001, 2002, 2003 e 2004).

\section{MATERIAL E MÉTODOS}

\section{Instalação e condução do experimento}

Para este estudo, utilizou-se de dados de produção acumulada do período de 16 de outubro de 1997 a 30 de junho de 2004 (seis colheitas), obtidos em experimento conduzido no Departamento de Engenharia da Universidade Federal de Lavras, localizada no município de Lavras, no Estado de Minas Gerais, a uma altitude de 918 m, latitude sul de $21^{\circ} 45^{\prime}$ e longitude oeste de $45^{\circ} 00^{\prime}$, ocupando uma área de aproximadamente 0,24 ha.

O cafeeiro utilizado no experimento foi a cultivar "Acaiá Cerrado" (MG-1474), plantado em março de 1997, num espaçamento de 3,0 x 0,6 m. Para garantir o "pegamento" das mudas, todas as plantas foram irrigadas por aspersão até agosto de 1997. A partir de outubro de 1997, iniciou-se a aplicação dos tratamentos, que foram quatro lâminas de irrigação $(0 \%, 40 \%, 60 \%, 80 \%$ e 100\% da evaporação do Tanque Classe A). As lâminas de água aplicadas foram calculadas através do balanço entre a evaporação do Tanque Classe A (ECA) e as precipitações ocorridas no período entre duas irrigações consecutivas. $\mathrm{O}$ delineamento experimental utilizado foi $\mathrm{o}$ de blocos casualizados, com quatro repetições, contendo trinta plantas em cada parcela, considerando-se como parcela útil vinte e quatro plantas.

Para o procedimento de estimativa do custo de produção, utilizou-se como estrutura do custo total de produção, do cálculo da depreciação e do custo alternativo (REIS, 2002). O período avaliado para o cálculo dos custos foi de 6,7 anos (período entre 16 de outubro de 1997 e 30 de junho de 2004).

O critério adotado para correção de valores foi o de preço único, ou seja, somam-se as quantidades utilizadas durante o ano, e o resultado é multiplicado pelo preço vigente em determinada data. Para este trabalho, considerou-se o preço médio de junho de 2004, que foi $\mathrm{R} \$ 212,00$ por saca de $60 \mathrm{~kg}$ (AGRIANUAL, 2005).

\section{Análise estatística}

Foram efetuadas as análises de regressão, a fim de verificar a correlação entre a variável dependente (produtividade) e a variável independente (lâmina de irrigação). Foram consideradas como melhores equações aquelas que apresentaram maior coeficiente de determinação $\left(\mathrm{R}^{2}\right)$.

\section{Estimativa do custo de produção}

Utilizou-se para a estimativa do custo de produção, conceituado como a soma de valores de todos os recursos (insumos) e operações (serviços) utilizados no processo produtivo de certa atividade, incluindo os respectivos custos alternativos ou de oportunidade, o procedimento que considera os custos oportunidade (REIS, 2002). 
Para estimar o custo de produção, neste trabalho, utilizou-se de valores em $\mathrm{R} \$$ com base nas seguintes informações: lavoura em produção de 22 ha, período de uma safra (um ano agrícola) e nos custos fixos e variáveis detalhados a seguir.

\section{Capital investido}

Terra: a terra não se deprecia, haja vista que se parte da hipótese de que o cafeicultor adota um manejo de solo adequado, repondo à terra todos os elementos químicos retirados pela planta, através das adubações, e são realizadas práticas conservacionistas, que mantêm as suas características. O valor considerado é o seu custo alternativo, baseado no aluguel da terra explorada. $\mathrm{O}$ aluguel foi considerado como sendo um litro de leite $\mathrm{ha}^{-1} \mathrm{~d}^{-1}$, pois este é um dos procedimentos mais utilizados na região sul mineira. $\mathrm{O}$ preço utilizado de um litro de leite foi $\mathrm{R} \$ 0,30$, ou seja, $\mathrm{R} \$ 9,00 \mathrm{ha}^{-1} \mathrm{mês}^{-1}$.

Formação da Lavoura: para a formação da lavoura considerou-se o custo médio obtido no período de junho de 2004 (AGRIANUAL, 2005). Realizou-se a depreciação, utilizando-se como vida útil da lavoura 15 anos.

Benfeitorias: considerou-se como benfeitorias: tulha, armazém, galpão de máquinas, depósito, casa de colono, terreiro de café, instalação elétrica, sistema de comunicação e estradas, com valor total e exclusivo para a cafeicultura de $\mathrm{R} \$ 34.807,00$. Para este valor, considerou-se vida útil média de 30 anos e idade média das benfeitorias de 16 anos.

Máquinas e equipamentos: o valor considerado para máquinas e equipamentos (trator, grade, roçadeira, carreta, pulverizador, adubadeira, subsolador, sulcador e lâmina, distribuidor de calcário, lavador de café, secador de café, máquina de beneficiar, automóvel de serviço e ferramentas diversas) foi o valor total e exclusivo para café de $\mathrm{R} \$ 56.309,00$. Como valor residual, considerou-se $20 \%$ do valor inicial ( $\mathrm{R} \$ 11.261,80)$.

Imposto territorial rural (ITR): foi considerado $\mathrm{R} \$ 0,11 \mathrm{ha}^{-1} \mathrm{ano}^{-1}$, conforme citado nos índices de preços agrícolas do Departamento de Administração e Economia da Universidade Federal de Lavras (UFLA).

Sistema de irrigação: o custo de um sistema de irrigação varia muito. Neste trabalho, o custo foi relativo a um projeto com as seguintes características: conjunto motobomba $25 \mathrm{cv}$, área 22 ha, chave de partida direta com contactor e relé, controlador eletrônico, injetor de fertilizantes tipo venturi com bomba reforço, válvulas de ar e vácuo, válvulas elétricas com solenoides, válvula de alívio, adutora de aço de $200 \mathrm{~m}$ até o cabeçal, cabeçal até os setores de PVC, tubo gotejador autocompensante com vazão $2,3 \mathrm{~L} \mathrm{~h}^{-1}$ com espaçamento de $0,75 \mathrm{~m}$, dois filtros de disco com retrolavagem automática e desnível do terreno de $55 \mathrm{~m}$, valor total e exclusivo para café de $\mathrm{R} \$ 101.200,00$. A vida útil considerada foi de 15 anos.

Calagem: os gastos com calagem $\left(\mathrm{R} \$ 78,15 \mathrm{ha}^{-1}\right)$ foram considerados custo fixo por a reposição ocorrer a cada dois anos.

Depreciação: o método de depreciação utilizado foi o linear, conforme eq.(1):

$$
\text { Depreciação }=\frac{\text { Valor atual }- \text { Valor residual }}{\text { Vida útil }}
$$

O custo fixo de cada item do capital investido foi calculado somando-se a depreciação e o custo alternativo do recurso, conforme apresentado a seguir.

Custo alternativo fixo $\left(\mathbf{C A}_{\text {fixo }}\right)$ : calculado a uma taxa de juros real de $12 \%$ a.a., para cada item dos recursos variáveis empregados no processo produtivo da cafeicultura. No seu cálculo, quando a idade média de uso do bem era conhecida, utilizou-se a eq.(2): 


$$
\mathrm{CA}_{\text {fixo }}=\frac{\mathrm{V}_{\mathrm{u}}-\mathrm{I}}{\mathrm{V}_{\mathrm{u}}} \mathrm{V}_{\mathrm{a}} \mathrm{TJ}
$$

em que,

$\mathrm{V}_{\mathrm{a}}$ - valor atual do recurso;

$\mathrm{V}_{\mathrm{u}}$ - vida útil (período em anos que determinado bem é utilizado na atividade), anos;

I - idade média de uso do bem, anos, e

TJ - taxa de juros, decimal.

Quando não se conhecia a idade média de uso do bem, usou-se a eq.(3) para o cálculo do $\mathrm{CA}_{\text {fixo: }}$ :

$$
\mathrm{CA}_{\text {fixo }}=\frac{\mathrm{V}_{\mathrm{a}}}{2} \mathrm{TJ}
$$

ou seja, considerou-se o $\mathrm{CA}_{\text {fixo }}$ como se a idade de uso dos recursos fixos fosse $50 \%$ da vida útil $(\mathrm{Vu})$, que resulta na metade do valor atual do recurso (Va), multiplicado pela taxa de juros.

\section{Custo Variável}

O custo de cada recurso variável foi calculado pelo desembolso realizado para aquisição de produtos e serviços, somado ao custo alternativo. Os recursos variáveis e a forma de operacionalização utilizada foram:

Mão de obra: os custos com mão de obra, gastos na safra com operação do sistema de irrigação, administrador, capataz, tratorista e diaristas, envolvendo todas as operações de manutenção da cultura, colheita, terreiro, etc., foram calculados conforme sugere MENDONÇA (2001).

Insumos: correspondem ao gasto com aquisição de fertilizantes químicos e defensivos.

Máquinas e implementos: gastos com máquinas, equipamentos e veículos, para funcionamento e manutenção (combustíveis, lubrificantes, peças de reposição, serviços mecânicos).

Despesas gerais: secagem, conservação das benfeitorias e outros.

Utensílios para colheita e ferramentas: referem-se a gastos com rastelões, rastelos, rodos, sacas de $60 \mathrm{~L}$, peneiras, carrinhos de mão, escovões, lonas 5 × $6 \mathrm{~m}$, enxadas, foices, limas, enxadões, pás, etc.

Energia: o custo com energia (CE) foi calculado conforme a eq.(4), sugerida por MENDONÇA (2001):

$$
\mathrm{CE}=\mathrm{V}_{\mathrm{kwh}} \mathrm{T} \frac{736 \mathrm{Pot}}{1000 \eta}
$$

em que,

$\mathrm{V}_{\mathrm{kwh}}$ - valor do $\mathrm{kWh}$

$\mathrm{T}$ - tempo total de funcionamento do sistema de irrigação, h;

Pot - potência do conjunto motobomba, cv;

$\eta$ - rendimento do conjunto motobomba em decimal, e

736 - fator de transformação da potência de cv para kWh.

O valor do kWh utilizado foi de R\$ 0,14, conforme tarifa da Companhia Energética de Minas Gerais/CEMIG.

Água: a cobrança pelo uso da água é um dos importantes instrumentos de gestão estabelecidos pela Lei $\mathrm{n}^{\mathrm{o}}$ 9.433, de 8 de janeiro de 1997, e tem como objetivo central reconhecer a água como um bem econômico, promover a racionalização de seu uso, criar as condições de equilíbrio entre as forças da oferta e da demanda, promovendo, em consequência, a harmonia entre 
os usuários competidores e, ao mesmo tempo, gerar fundo financeiro para as obras, programas e intervenção na bacia que deu origem. Apesar de sua complexidade, a adoção do instrumento de cobrança pelo uso dos recursos hídricos está em fase de implantação. Neste trabalho, optou-se por considerar 0,5\% a.m. dos custos de produção.

Para o cálculo do custo alternativo variável $\left(\mathrm{CA}_{\mathrm{var}}\right)$, utilizou-se a eq.(5):

$$
\mathrm{CA}_{\text {var }}=\mathrm{V}_{\text {gasto }} \mathrm{TJP}
$$

em que,

$\mathrm{V}_{\text {gasto }}$ - desembolso financeiro realizado pelo produtor para adquirir insumos e serviços necessários para a produção agrícola;

TJ - taxa de juros, e

$\mathrm{P}$ - preço do produto.

\section{Análise econômica simplificada}

A análise econômica permite identificar se o empreendimento está operando com lucro, ou seja, se e como os recursos empregados no processo de produção estão sendo remunerados, além de verificar como está a rentabilidade da atividade em questão, comparada a outras alternativas de emprego do tempo e capital. Para esta análise, considerou-se a situação da Figura 1, conforme descrita por REIS (2002).

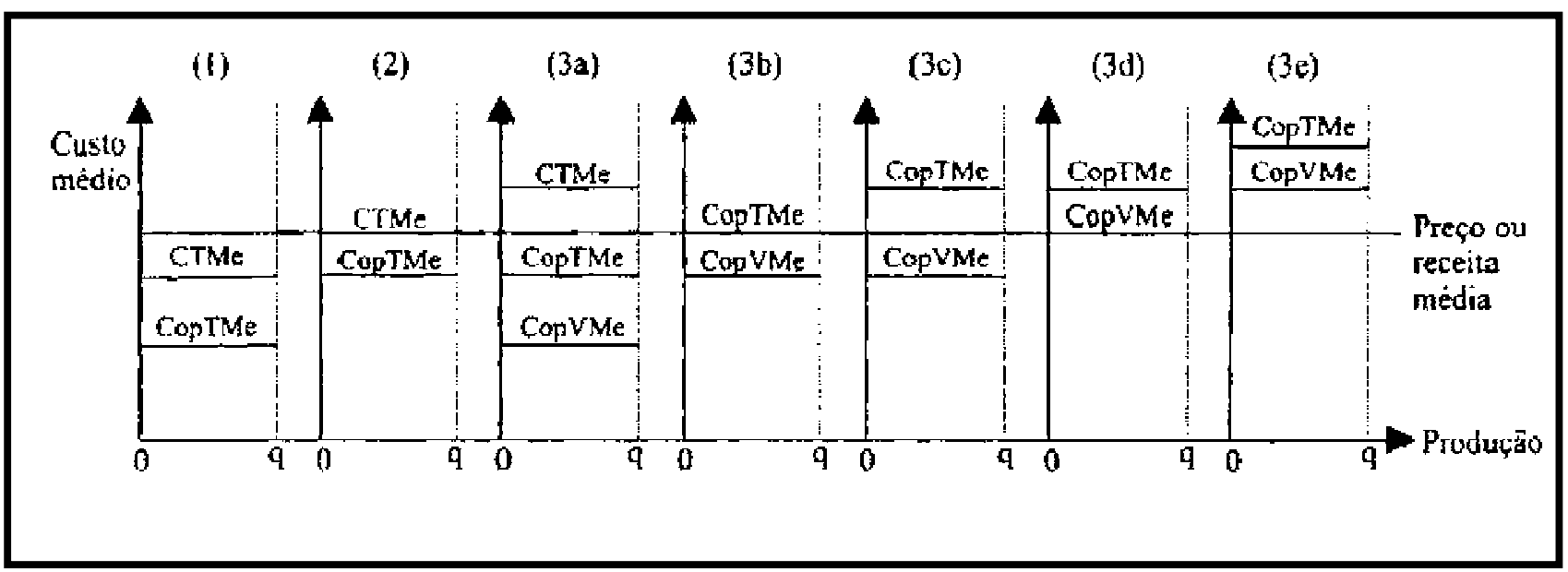

FIGURA 1. Situações de análises econômica e operacional de uma atividade produtiva (REIS, 2002). Situations of economic and operational analysis of a productive activity, Reis (2002).

O custo operacional corresponde ao valor monetário dos recursos utilizados no processo de produção, para repor os insumos variáveis (curto prazo) e fixos (longo prazo). O CopVMe (custo operacional variável médio) é diretamente proporcional ao CopVT (custo operacional variável total). Os CVMe (custo variável médio) e CVT (custo variável total) também mantêm essa mesma relação de proporcionalidade. O CopVT (custo operacional variável total) e CAV (custo alternativo variável) compõem o CVT (custo variável total). Os dados foram compilados em planilha eletrônica, calculados os custos, e a receita total e líquida. Por lucro, entendeu-se como a diferença entre a receita total (produção vezes preço do produto) e custo total.

\section{RESULTADOS E DISCUSSÃO}

Verificou-se que as lâminas de irrigação interferiram na produtividade de maneira significativa, a $1 \%$ de probabilidade, como mostra os dados da Tabela 1. 
TABELA 1. Análise de variância da produtividade em função dos tratamentos de lâminas de irrigação aplicadas. Yield analysis of variance as a function of the irrigation treatments applied.

\begin{tabular}{ccc}
\hline Fator de Variação & G.L. & QM \\
\hline Lâminas & 4 & $41.337,56^{*}$ \\
Bloco & 3 & $2.384,87^{\mathrm{ns}}$ \\
Resíduo & 12 & $4.370,15$ \\
\hline Total & 19 & \\
\hline Média Geral & & 409,60 \\
C.V. & & $16,14 \%$ \\
\hline
\end{tabular}

* significativo a $1 \%$ de probabilidade ${ }^{\mathrm{ns}}$ - não significativo

Analisando-se as médias de produtividade do café, apresentadas na Tabela 2, verificou-se que foram crescentes (em valores absolutos) e que o tratamento que recebeu a lâmina de irrigação de $100 \%$ da Evaporação do Tanque Classe A, foi o que atingiu a maior produção acumulada, nas seis safras analisadas, obtendo-se em média 477,37 saca.ha $^{-1}$ e que, na área não irrigada, a produtividade média acumulada foi de 317,13 saca.ha ${ }^{-1}$, equivalente a 33,57\% inferior à irrigação a $100 \%$.

Na análise estatística da produção, o tratamento $100 \%$ da ECA só foi diferente do tratamento não irrigado, sendo considerado semelhante aos demais. Porém, economicamente, o resultado foi diferente, conforme pode ser observado pelos resultados de custo de produção de cada saca de café beneficiado apresentado no item correspondente.

TABELA 2. Dados de produtividade média e acumulada, em sacas ha ${ }^{-1}$, de seis safras, em função das diferentes lâminas de irrigação aplicadas. Average and accumulated productivity data in sacks.ha ${ }^{-1}$ of six seasons, according to the different irrigation applied.

\begin{tabular}{|c|c|c|c|c|c|c|c|}
\hline \multirow{2}{*}{$\begin{array}{c}\text { Tratamento } \% \\
\text { ECA }\end{array}$} & \multicolumn{7}{|c|}{ Produtividade - sacas ha ${ }^{-1}$} \\
\hline & 1999 & 2000 & 2001 & 2002 & 2003 & 2004 & TOTAL \\
\hline $\mathrm{L}_{0}$ & 46,81 & 34,19 & 36,25 & 86,20 & 17,69 & 95,98 & $317,13 \mathrm{~b}$ \\
\hline $\mathrm{L}_{40}$ & 58,67 & 60,61 & 34,03 & 99,50 & 29,35 & 119,80 & $401,96 \mathrm{ab}$ \\
\hline $\mathrm{L}_{60}$ & 62,12 & 71,65 & 35,68 & 102,96 & 27,05 & 120,57 & $420,01 \mathrm{ab}$ \\
\hline $\mathrm{L}_{80}$ & 58,81 & 80,83 & 33,25 & 112,65 & 19,89 & 126,16 & $431,58 \mathrm{ab}$ \\
\hline $\mathrm{L}_{100}$ & 72,02 & 84,95 & 47,77 & 112,70 & 31,77 & 128,16 & $477,37 \mathrm{a}$ \\
\hline
\end{tabular}

\section{Custo total de produção}

As informações contidas na Tabela 3 expressam, em $\mathrm{R} \$$ ha $^{-1}$, os custos fixos e variáveis dos recursos utilizados na produção de café, nos diferentes tratamentos de reposição de lâminas de água utilizados.

Entre os tratamentos irrigados, houve aumento do custo total, em função do aumento das lâminas de água aplicadas (Tabela 3), os quais apresentaram valores crescentes na produção média acumulada de grãos, sendo que o tratamento que aplicou $100 \%$ da Evaporação do Tanque Classe A $\left(\mathrm{L}_{100}\right)$ foi o que proporcionou a maior produtividade média, de 79,50 sacas ha ${ }^{-1}$ (Tabela 2), portanto com a maior eficiência técnica no uso da irrigação.

Os fatores que mais contribuíram para o aumento do custo total na área irrigada foram os custos variáveis, tais como mão de obra e energia. Todavia, os mesmos foram compensados pelo aumento na produtividade dos grãos. O tratamento não irrigado foi o que apresentou o menor custo total e a menor produtividade $\left(52,88\right.$ sacas $\left.^{-1}\right)$. 
TABELA 3. Custos fixos e variáveis, em $\mathrm{R} \$$, da produção do cafeeiro, em diferentes tratamentos de lâmina de água. Fixed and variable costs, in $\mathbf{R} \$$, of coffee yield in different treatments of drip irrigation.

\begin{tabular}{crrrrr}
\hline \multirow{2}{*}{ Custos Fixos e Variáveis } & \multicolumn{5}{c}{ Tratamentos } \\
\cline { 2 - 5 } Terra & \multicolumn{1}{c}{$\mathrm{L}_{0}$} & \multicolumn{1}{c}{$\mathrm{L}_{40}$} & \multicolumn{1}{c}{$\mathrm{L}_{60}$} & \multicolumn{1}{c}{$\mathrm{L}_{80}$} & \multicolumn{1}{c}{$\mathrm{L}_{100}$} \\
\hline Formação da lavoura (depreciação + CA) & 108,00 & 108,00 & 108,00 & 108,00 & 108,00 \\
Benfeitorias & 475,96 & 475,96 & 475,96 & 475,96 & 475,96 \\
Máquinas e Equipamentos & 141,34 & 141,34 & 141,34 & 141,34 & 141,34 \\
ITR & 212,52 & 212,52 & 212,52 & 212,52 & 212,52 \\
Sistema de Irrigação & 0,01 & 0,01 & 0,01 & 0,01 & 0,01 \\
Calagem & - & 896,00 & 896,00 & 896,00 & 896,00 \\
Custo Fixo Total (CFT) & 48,45 & 48,45 & 48,45 & 48,45 & 48,45 \\
\hline Mão de obra & 986,27 & $1.882,27$ & $1.882,27$ & $1.882,27$ & $1.882,27$ \\
\hline Insumos & $1.713,31$ & $2.214,83$ & $2.312,35$ & $2.374,88$ & $2.622,09$ \\
Gastos com máquinas e equipamentos & $1.430,59$ & $1.430,59$ & $1.430,59$ & $1.430,59$ & $1.430,59$ \\
Energia elétrica & $4.174,53$ & $4.174,53$ & $4.174,53$ & $4.174,53$ & $4.174,53$ \\
Água & 132,20 & $1.398,20$ & $1.437,20$ & $1.477,20$ & $1.516,20$ \\
Utensílios para colheita e ferramentas & 600,00 & 118,43 & 118,43 & 118,43 & 118,43 \\
Despesas gerais & $1.200,00$ & $1.200,00$ & 600,00 & 600,00 & 600,00 \\
\hline Subtotal do Custo Variável Total(CopVT) & $9.250,63$ & $11.232,76$ & $11.273,10$ & $11.375,63$ & $11.661,84$ \\
\hline Custo alternativo & 555,04 & 673,97 & 676,39 & 682,54 & 699,71 \\
Custo Variável Total & $9.805,67$ & $11.906,73$ & $11.949,49$ & $12.058,17$ & $12.361,55$ \\
\hline Custo Total (CT) & $10.791,94$ & $13.789,00$ & $13.831,76$ & $13.940,44$ & $14.243,82$ \\
\hline Produtividade (sacas ha ${ }^{-1}$ ) & 52,88 & 66,99 & 70,00 & 71,93 & 79,50 \\
\hline Receita média (Rme)* & 212,00 & 212,00 & 212,00 & 212,00 & 212,00 \\
\hline Receita Total & $11.210,56$ & $14.201,88$ & $14.840,00$ & $15.249,16$ & $16.854,00$ \\
\hline Lucro/Prejuízo & 418,62 & 412,88 & $1.008,24$ & $1.308,72$ & $2.610,18$ \\
\hline
\end{tabular}

$\mathrm{L}_{\mathrm{O}}-\mathrm{s} /$ irrigação; $\mathrm{L}_{40}-40 \% \mathrm{ECA} ; \mathrm{L}_{60}-60 \% \mathrm{ECA} ; \mathrm{L}_{80}-80 \%$ ECA; $\mathrm{L}_{100}-100 \%$ ECA. (*) Receita média: preço médio obtido pela ESALQ/BM\&F - café tipo 6/bebida dura.

\section{Análise econômica simplificada}

Os custos médios observados na produção de grãos do café, em relação aos diferentes tratamentos de lâminas de irrigação, estão apresentados na Tabela 4. Estes dados foram usados para a realização da análise econômica deste estudo, considerando-se como preço médio da saca de café o valor de R \$212,00, correspondente ao mês de junho de 2004 (AGRIANUAL, 2005).

Observou-se que o tratamento sem irrigação $\left(\mathrm{L}_{0}\right)$ apresentou um custo total médio de $\mathrm{R} \$ 204,08 \mathrm{saca}^{-1}$, enquanto na área irrigada o custo total médio foi sendo reduzido à medida que se aumentava a lâmina de água aplicada, sendo que, no tratamento que recebeu a lâmina de irrigação de $100 \%$ da ECA $\left(\mathrm{L}_{100}\right)$, o custo total médio foi o menor ( $\left.\mathrm{R} \$ 179,17 \mathrm{saca}^{-1}\right)$, em função de sua maior produtividade, o que corresponde a um ganho de $12,21 \%$, quando comparado com os tratamentos que não receberam irrigação.

Entretanto, tanto na condição sem irrigação como na irrigada, o custo total médio da saca produzida foi inferior ao preço de venda considerado.

$\mathrm{Na}$ análise econômica feita nas duas situações consideradas (área sem irrigação e área irrigada), ambas apresentaram uma situação de lucro supernormal (situação em que a atividade está obtendo retorno maior que a alternativa considerada de emprego do capital). Nesse caso, os custos totais médios (CTMe) de cada tratamento foram inferiores à receita média ( $\mathrm{RMe})$, e a tendência a médio e longo prazos é de expansão e da entrada de novas empresas para a atividade, atraindo investimentos competitivos. 
TABELA 4. Custos econômicos e operacionais médios por saca de $60 \mathrm{~kg}$ da produção de café, em diferentes tratamentos de lâmina de irrigação, provenientes de seis safras acumuladas, do cafeeiro (Coffea arabica L.) Acaiá MG-1474. Average economical and operational costs per sack of $60 \mathrm{~kg}$ of coffee production in different treatments of irrigation from six accrued seasons of coffee (Coffea arabica L.) Acaiá MG-1474.

\begin{tabular}{crrrrrr}
\hline \multirow{2}{*}{ Tratamento } & CFMe & CVMe & CTMe & CopFMe & CopVMe & CopTMe \\
\cline { 2 - 6 } & \multicolumn{5}{c}{$\mathrm{R} \$$} \\
\hline $\mathrm{L}_{0}$ & 18,65 & 185,43 & 204,08 & 12,44 & 174,94 & 187,38 \\
$\mathrm{~L}_{40}$ & 28,10 & 177,74 & 205,84 & 9,82 & 167,68 & 177,50 \\
$\mathrm{~L}_{60}$ & 26,89 & 170,71 & 197,60 & 9,40 & 161,04 & 170,40 \\
$\mathrm{~L}_{80}$ & 26,10 & 167,64 & 193,81 & 9,15 & 158,15 & 167,30 \\
$\mathrm{~L}_{100}$ & 23,68 & 155,49 & 179,17 & 8,28 & 146,69 & 154,97 \\
Média & 24,68 & 171,40 & 196,10 & 9,82 & 161,70 & 171,51 \\
\hline
\end{tabular}

CFMe - custo fixo médio; CVMe - custo variável médio; CTMe - custo total médio; CopFMe - custo operacional fixo médio; CopVMe - custo operacional variável médio; CopTMe - custo operacional total médio

\section{Ponto de nivelamento}

A produção mínima, por tratamento aplicado, no qual a receita total foi igual ao custo total $(\mathrm{RT}=\mathrm{CT})$, bem como a produtividade média acumulada estão indicadas na Tabela 5 .

TABELA 5. Ponto de nivelamento e a produtividade média, do café, em diferentes tratamentos de lâmina de irrigação, provenientes de seis safras acumuladas, do cafeeiro (Coffea arabica L.). Breakeven point and the average productivity of coffee in different irrigation treatments, from 6 harvests of coffee (Coffea arabica L.) accumulated.

\begin{tabular}{ccc}
\hline Tratamento & $\begin{array}{c}\text { Ponto Nivelamento } \\
\left(\text { sacas ha }^{-1}\right)\end{array}$ & $\begin{array}{c}\text { Produtividade Média } \\
\left(\text { sacas ha }^{-1}\right)\end{array}$ \\
\hline $\mathrm{L}_{0}$ & 50,90 & 52,88 \\
$\mathrm{~L}_{40}$ & 65,04 & 66,99 \\
$\mathrm{~L}_{60}$ & 65,24 & 70,00 \\
$\mathrm{~L}_{80}$ & 65,76 & 71,93 \\
$\mathrm{~L}_{100}$ & 67,19 & 79,50 \\
\hline
\end{tabular}

É interessante observar que as produções acima do ponto de equilíbrio foram de: 1,$98 ; 1,96$; 4,76; 6,17 e 12,31 sacas ha ${ }^{-1}$ para os respectivos tratamentos $\mathrm{L}_{0}, \mathrm{~L}_{40}, \mathrm{~L}_{60}, \mathrm{~L}_{80}$ e $\mathrm{L}_{100}$. A lâmina $\mathrm{L}_{40}$ corresponde à situação em que o produtor teria o menor lucro. No tratamento $\mathrm{L}_{100}$, observaram-se as maiores produções em sacas, acima do ponto de nivelamento.

Como o preço de venda do produto considerado foi de $\mathrm{R} \$ 212,00 \mathrm{saca}^{-1}$, a lucratividade média por hectare foi de: $\mathrm{R} \$ 418,62 ; \mathrm{R} \$ 412,88 ; \mathrm{R} \$ 1.008,24 ; \mathrm{R} \$ 1.308,72$ e $\mathrm{R} \$ 2.610,18$ para os respectivos tratamentos $\mathrm{L}_{0}, \mathrm{~L}_{40}, \mathrm{~L}_{60}, \mathrm{~L}_{80}$ e $\mathrm{L}_{100}$. Portanto, a irrigação com reposição de $100 \%$ da Evaporação do Tanque Classe A promoveu uma lucratividade superior aos demais, de 15,82\%.

Estes resultados encontrados foram diferentes dos encontrados por SILVA et al., (2003), que relataram que a situação dos cafeicultores que utilizaram como reposição de água no solo $100 \%$ da ECA era de resíduo positivo (preço > CopTMe), ou seja, parte do custo alternativo do capital empregado na atividade cafeeira não foi reembolsada, entretanto, no período analisado por esses autores, o preço da saca de $60 \mathrm{~kg}$ de café beneficiado foi de R \$120,00. Já para SILVA et al. (2006), com o preço de $\mathrm{R} \$ 92,50$ a saca de café de $60 \mathrm{~kg}$, fica economicamente impossível sustentar a atividade. Portanto, é importante estar atento à flutuação de preços do produto, pois a viabilidade econômica da atividade está diretamente relacionada com o preço de venda do mesmo, o que leva a diferentes respostas fornecidas quanto à viabilidade econômica da atividade cafeeira. 


\section{CONCLUSÕES}

Nas condições analisadas e considerando-se o preço de venda de R \$212,00 por saca de café beneficiado, pôde-se concluir que a produção de café no sul de Minas é economicamente viável em áreas não irrigadas, desde que a produtividade média seja de, no mínimo, 50,90 sacas por hectare.

A irrigação por gotejamento da cultura do cafeeiro é viável economicamente para o município de Lavras - MG, pois o aumento de produtividade real de 33,48\%, ocorrido com a irrigação, proporcionou maiores lucros.

Em áreas irrigadas, uma produtividade média de 67,19 sacas de café, em seis safras consecutivas, é suficiente para se atingir o ponto de nivelamento, ou seja, os custos totais da atividade são iguais à receita total.

O manejo da irrigação pode ser feito usando-se a lâmina de reposição de $100 \%$ da Evaporação do Tanque Classe A (ECA).

\section{REFERÊNCIAS}

AGRIANUAL 2005: anuário da agricultura brasileira. São Paulo: FNP Consultoria e Comércio, 2005. $520 \mathrm{p}$.

ALVES, M.E.B. Resposta do cafeeiro (Coffea arabica L.) a diferentes lâminas de irrigação e fertirrigação. 1999. 93 f. Dissertação (Mestrado) - Universidade Federal de Lavras, Lavras, 1999.

BASTOS, E.A.; FOLEGATTI, M.V.; ANDRADE JÚNIOR, A.S.; CARDOSO, M.J.; FARIA, R.T. Manejo econômico da irrigação de feijão-caupi via modelo de simulação. Irriga, Botucatu, v.5, n.2, p.84-98, 2000.

FARIA, M.A.; REZENDE, F.C. Cafeicultura empresarial: produtividade e qualidade - irrigação na cafeicultura. Lavras: UFLA/FAEPE, 1997. 110 p. (Curso de Especialização Lato Sensu por Tutoria a Distância).

FRIZZONE, J.A.; BOTREL, T.A.; FREITAS, H.A.C. Análise comparativa dos custos de irrigação por pivô central, em culturas de feijão, utilizando energia elétrica e óleo diesel. Engenharia Rural, Piracicaba, v.5, n.1, p.34-53, 1994.

GROSSI, J.C. Administrar o agronegócio do café é o maior desafio. Preços Agrícolas, São Paulo, v.12, n.142, p.8, ago. 1998.

MANTOVANI, E.C.; SOARES, A. R. Irrigação do cafeeiro: informações técnicas e coletânea de trabalhos. Viçosa: Associação dos Engenheiros Agrícolas de Minas Gerais/UFV, DEA, 2003. $260 \mathrm{p}$.

MARTIN, N.B.; VEGRO, C.L.R.; MORICOCHI, L. Custos e rentabilidade de diferentes sistemas de produção de café. Informações Econômicas, São Paulo, v.25, n.8, p.131-142, 1995.

MENDONÇA, F.C. Evolução dos custos e avaliação econômica de sistemas de irrigação utilizados na cafeicultura. In: ENCONTRO NACIONAL DE IRRIGAÇÃO DA CAFEICULTURA NO CERRADO, 6., 2000, Uberlândia. Anais... Uberlândia: UFU, 2001. 212 p.

REIS, R.P. Fundamentos da economia aplicada. Lavras: UFLA/FAEPE, 2002. 91 p.

RODRIGUEZ, F. Custos e benefícios da irrigação no Brasil. ITEM: Irrigação e Tecnologia Moderna, n.41, p.6-11, 1990.

SANTINATO, R.; FERNANDES, A.L.T.; FERNANDES, D.R. Irrigação na cultura do café. Campinas: Arbore, 1996. 146 p.

SILVA, A.L.; FARIA, M.A.; REIS, R.P. Viabilidade técnico-econômica do uso do sistema de irrigação por gotejamento na cultura do cafeeiro. Revista Brasileira de Engenharia Agrícola e Ambiental, Campina Grande, v.7, n.1, p.34-74, 2003.

SINDICATO E ORGANIZAÇÃO DAS COOPERATIVAS DO ESTADO DO PARANÁ. Custos de produção de café: estudo comparativo entre o sistema de produção adensado e o sistema de produção tradicional. Curitiba, 2000. 110 p. 